\title{
Impact of Photosensitization on Physicochemical Properties in Strawberries ${ }^{+}$
}

\author{
Shammy Sarwar ${ }^{1, *}$, Ram Mereddy ${ }^{2}$, Michael E. Netzel ${ }^{3}$, Gabriele Netzel ${ }^{3}$ \\ and Yasmina Sultanbawa ${ }^{3}$ \\ 1 Queensland Alliance for Agriculture and Food Innovation (QAAFI), The University of Queensland, \\ Coopers Plains, P.O. Box 156, Archerfiled BC, QLD 4108, Australia \\ 2 Department of Agriculture and Fisheries, Coopers Plains, P.O. Box 156, \\ Archerfiled BC, QLD 4108, Australia; ram.mereddy@daf.qld.gov.au \\ 3 Queensland Alliance for Agriculture and Food Innovation (QAAFI), The University of Queensland, \\ Coopers Plains, P.O. Box 156, Archerfiled BC, QLD 4108, Australia; m.netzel@uq.edu.au (M.E.N.); \\ g.netzel@uq.edu.au (G.N.); y.sultanbawa@uq.edu.au (Y.S.) \\ * Correspondence: shammy.sarwar@uq.edu.au \\ + Presented at the third International Tropical Agriculture Conference (TROPAG 2019), Brisbane, Australia, \\ 11-13 November 2019.
}

Published: 21 January 2020

\begin{abstract}
Strawberries, depending on the cultivar and environmental conditions, can be a rich source of nutrients like folates and vitamin $C$ as well as bioactive phytochemicals, mainly polyphenols. But at room temperature, this fruit is highly perishable and has a relative short shelf life of only a couple of days. An innovative, cost effective and environmentally friendly technique, photosensitization, has been applied with the aim to extend the shelf life of strawberries and to minimize the loss of nutrients and also phytochemicals. Photosensitization works based on the combined action of photosensitizer, light and oxygen, which produce reactive oxygen species that inactivate microorganisms. Curcumin, known for its antifungal activity was used as the photosensitizer in this study. To see the effect of photosensitization, physicochemical parameters of both fresh and photosensitized strawberries have been tested. There were no significant $(\mathrm{p}<0.05)$ changes in $\mathrm{pH}$, titratable acidity, total soluble solids and moisture content between treated and untreated (control) strawberries. However, total sugar content of photosensitized strawberry was significantly $(\mathrm{p}<0.05)$ higher than that of the control $(5.29 \pm 0.26 \mathrm{~g} / 100 \mathrm{~g}$ FW vs. $4.12 \pm 0.13 \mathrm{~g} / 100 \mathrm{~g}$ FW). No significant difference was observed in the total phenolic content of the treated $(192.9 \pm 3.16 \mathrm{mg}$ gallic acid equivalents (GAE)/100 g FW) and the control (195.8 $\pm 3.05 \mathrm{mg}$ GAE/100 $\mathrm{g}$ FW) samples. These preliminary findings show that photosensitization could be a promising technique that has the potential to be used in the horticulture industry to extend the shelf life of fresh produce such as strawberries.
\end{abstract}

Keywords: photosensitization; total phenol content; horticulture

Funding: This research was supported in part by Hort Innovation Project “Naturally Nutritious" (HN 15001).

Acknowledgments: The authors would like to thank the Australian Government for awarding Research Training Program Scholarship.

Conflicts of Interest: The author declares no conflict of interest.

(C) 2020 by the authors. Licensee MDPI, Basel, Switzerland. This article is an open access article distributed under the terms and conditions of the Creative Commons Attribution (CC BY) license (http://creativecommons.org/licenses/by/4.0/). 